\title{
Mechanical Design and Fabrication Processes for the ALS Third-Harmonic Cavities
}

\author{
R. M. Franks \\ K. Hernandez \\ D. Otting \\ T. Henderson \\ D. Plate \\ R. A. Rimmer
}

This paper was prepared for submittal to the

1999 Particle Accelerator Conference

New York City, NY

March 27 - April 4, 1999

March 25, 1999

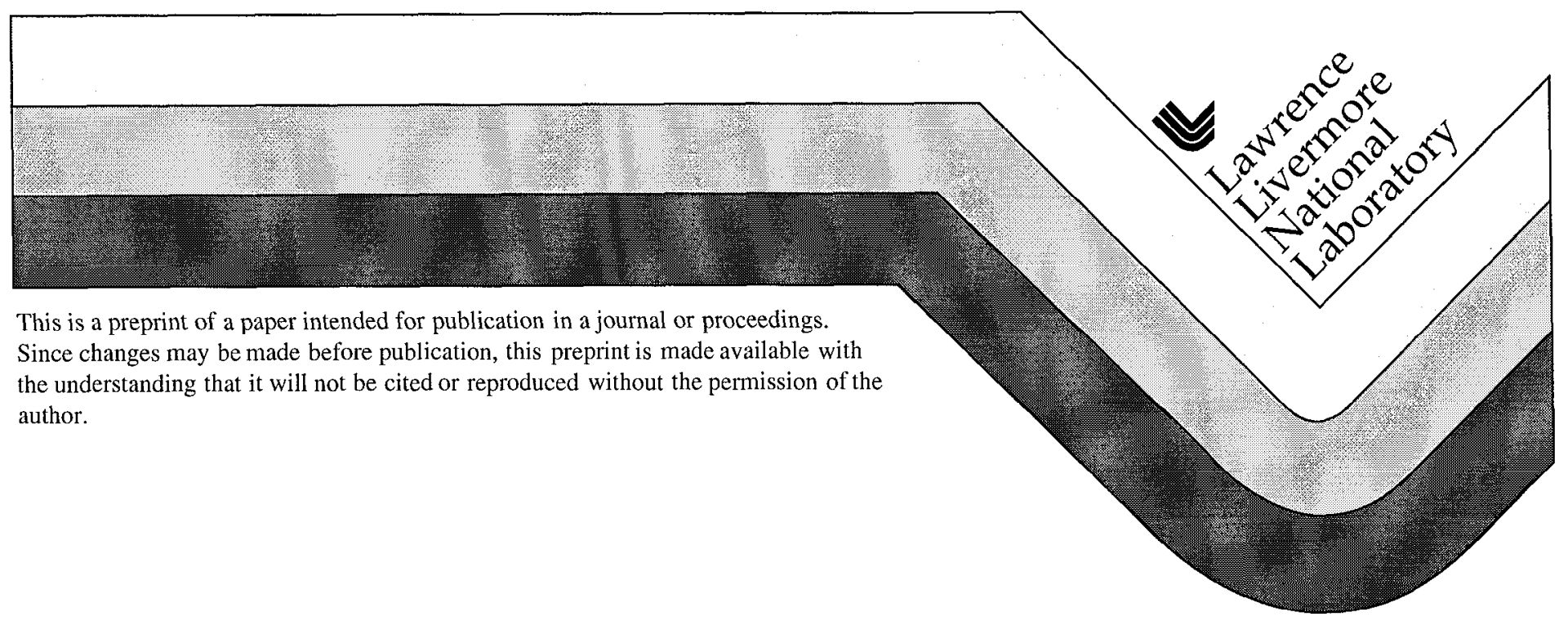




\section{DISCLAIMER}

This document was prepared as an account of work sponsored by an agency of the United States Government. Neither the United States Government nor the University of California nor any of their employees, makes any warranty, express or implied, or assumes any legal liability or responsibility for the accuracy, completeness, or usefulness of any information, apparatus, product, or process disclosed, or represents that its use would not infringe privately owned rights. Reference herein to any specific commercial products, process, or service by trade name, trademark, manufacturer, or otherwise, does not necessarily constitute or imply its endorsement, recommendation, or favoring by the United States Government or the University of California. The views and opinions of authors expressed herein do not necessarily state or reflect those of the United States Government or the Ciniversity of California, and shall not be used for advertising or product endorsement purposes. 


\title{
MECHANICAL DESIGN AND FÁBRICATION PROCESSES FOR THE ALS THIRD-HARMONIC CAVITIES ${ }^{*+}$
}

\author{
R.M. Franks", K. Hernandez, D. Otting, LLNL, PO Box 808 Livermore, CA 94551, USA \\ T. Henderson, D. Plate, R.A. Rimmer, LBNL, 1 Cyclotron Road, Berkeley, CA 94720, USA
}

\section{Abstract}

It is planned to install five third-harmonic $(1.5 \mathrm{GHz}) \mathrm{RF}$ Cavities in May/June 1999 as an upgrade to the Advanced Light Source (ALS) at Lawrence Berkeley National Laboratory (LBNL) [1]. This paper presents mechanical design features, our experiences in using electronic design models to expedite the manufacturing process, and the fabrication processes employed to produce these cavities for the ALS. We discuss some of the "lessons learned" from the PEP-II RF Cavity design and fabrication, and outline the improvements incorporated in the new design. We also report observations from our current effort.

\section{INTRODUCTION}

A minimal risk design and build cycle, to be accomplished in approximately 12 months, was desired for the ALS cavity upgrade. Upon investigation it was determined that the primary engineering, design, and fabrication issues involved in producing a third-harmonic cavity for ALS were very similar to those resolved during the Lawrence Livermore National Laboratory (LLNL) production of the PEP-II cavity [2]. It was decided to build upon this existing body of knowledge and incorporate lessons learned during PEP-II in order to achieve this goal [3].

\section{MECHANICAL DESIGN}

The design of the harmonic cavities employs many technologies developed for the PEP-II RF cavities, however, to mitigate design, schedule, and fabrication risk we sought to minimize the number of piece parts, processes, and 5-axis machining operations. The design focused on making the cavity body a spherical shape rather than the more conventional toroidal cavity shape. This allowed the port bodies to be lathe turned as integral parts of the cavity body rather than being fabricated separately and electron beam welded (EBW) to the cavity. We wanted to incorporate an end cap into the main cavity body to eliminate one piece-part and an EBW operation.

Additionally, to augment our use of conventional paper drawings, we desired to use the three- dimensional electronic design model as a fabrication tool to define tool path geometry.

*This work was supported by the US Department of Energy under contracts W-7405-ENG-48 (LLNL) DE-AC0376 SF00098 (LBNL). +http://kevlar.llnl.gov/3hrf $/ 3 \mathrm{hrf}$.htm \#Email: franks1@llnl.gov

\subsection{Design Reality}

The thickest plate readily available in UNS 10100 class 2 OFE copper [4] was determined to be 4.5 inch (114 mm) stock. This influenced the design since we could not include an end cap within this constraint; this drove the need for two end caps that are joined to the center body by EBW during the manufacturing sequence. Line of sight requirements for EBW resulted in shortening the beam ports and providing spool pieces to be joined after the end caps are EBW to the cavity body (Figure 1). While custom forged blanks would have enabled us to design an integral end cap, the long lead-time for forging was a prime factor in our decision to use the plate material.

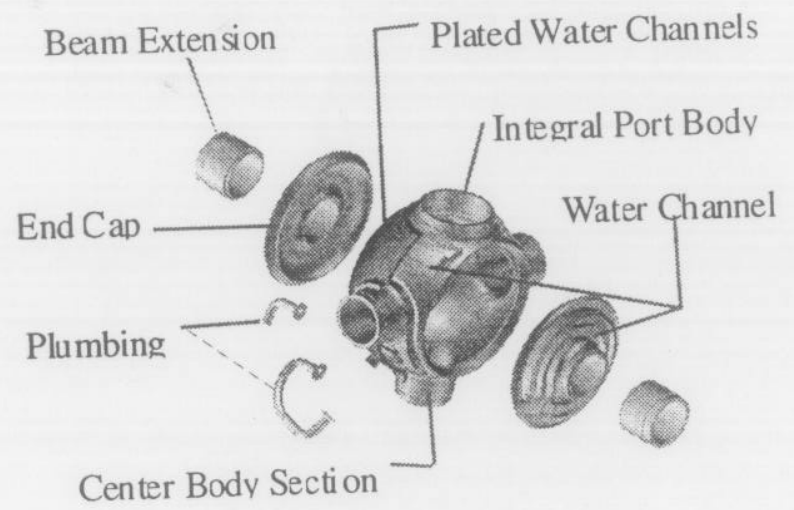

Figure 1: An exploded view (flanges omitted) of the ALS third-harmonic cavity showing integral equatorial port bodies, end caps, beam tube extensions, and plumbing.

\subsection{Design Model as a Manufacturing Tool}

The LBNL design team used Solid Designer (HP) CAD software to model the cavity, while LLNL's manufacturing operation used Pro-Engineer (Parametrix) CAM software to generate cutting path data for the NC machinery. By using IGES file format we were able to transfer information between the sites, however, while we could measure features and make tool programs we could not change any features in the model on the manufacturing system. This proved a bit cumbersome since, when several small design changes were needed, we had to replicate the entire translation, transfer, and verification sequence before manufacturing could access the modifications. Additionally, the complexity of defining water channel geometry in the manner we desired tended to overwhelm the file transfer mechanism and we had to 
produce the channel geometry in a Pro-Engineer model to generate the desired tool path programs.

\section{FABRICATION}

As the components progressed through the fabrication sequence the nomenclature evolved, the center body section was joined to one end cap and became the cavity body; after finishing the RF surface, tuning, and joining the final end cap, the cavity body became the RF cavity.

The center body, including the four round equatorial ports, was machined from a solid copper billet. The elimination of many joints and additional components outweighs the complexity introduced to the process by making the ports integral to the cavity body. The end caps, two per cavity, are machined from plate stock and remain identical parts for most of the fabrication process.

\subsection{Center Body Section}

The center body fabrication began with 4.5-inch $(114 \mathrm{~mm})$ thick by 11 inches $(279 \mathrm{~mm})$ square OFE Copper plates weighing approximately 155 pounds $(70 \mathrm{~kg})$ each. Initial work included rough boring a 3 -inch $(76.2 \mathrm{~mm})$ diameter hole through the blank and squaring the rough sawn sides. Additionally, 1-1/2 inch (38 mm) diameter holes were drilled at the four port positions spaced $90^{\circ}$ about the periphery of the body.

Accurate positioning and indexing of the blank throughout the entire fabrication process was deemed necessary; therefore, extra care was taken from the outset to establish consistency between blanks. With this in mind the central bore was machined to a diameter of 4.000 inches $(101.6 \mathrm{~mm})$ with a tolerance of $+/-.0005$ inch (.013 mm.) One face was also machined perpendicular to the bore at this time.

A horizontal $\mathrm{CNC}$ milling machine was used to remove the bulk of the excess material. Its CNC rotary table enabled accurate positioning of the body prior to making a $+/-.0005$ inch $(.013 \mathrm{~mm})$ bore in each port. These "identically" sized bores served as alignment points for the creation of datum features during the next operation.

Each cavity body was indexed four times to turn the port body and a segment of the spherical outer radius. Since close tolerances were maintained during the initial steps we were able to hold indicator runout to $t /-.0015$ inch $(.04 \mathrm{~mm})$ for each of the four indexed positions. We also counterbalanced the lathe fixture to minimize spindle vibrations due to the asymmetry of the fixture.

A horizontal CNC milling machine with a CNC rotary table was employed to cut the serpentine water channel into the copper body. The continuous channel is about 58 inches $(1.47 \mathrm{~m})$ long. These channels are about $3 / 8$ inch wide $\times 3 / 8$ inch deep $(10 \mathrm{~mm} \times 10 \mathrm{~mm})$ with a $3 / 32$ inch $(2.4 \mathrm{~mm})$ radius in the corners. A fully radiused channel would require a "ball" mill cutter that has zero cutting speed at its center point. The copper resists cutting freely under this condition, therefore we chose to have a flatbottomed channel with the small corner radii.

To eliminate 5-axis milling the sidewalls of the body channels were designed to be perpendicular to the beam axis rather than normal to the outer surface. This reduced programming and machining costs as well as minimizing the technical risk due to a less complex setup and program. Shallow counterbores were cut at the channel inlet and outlet points to locate the water fitting stubs that were plated into position during the water channel covering.

The RF surface was machined, leaving .080 inch (2 $\mathrm{mm}$ ) to be removed during the final machining stage, and the port bores were finished to within .01 inch $(.25 \mathrm{~mm})$.

\subsection{End Caps}

Two end caps, one designated "body end cap" the other "tuning end cap", were required. All end caps werc machined with $.080 \mathrm{inch}(2 \mathrm{~mm})$ to be removed at a later point in the fabrication process. A 39-inch (1-m) long cooling was cut into each end cap. At this point all surfaces of the tuning end cap were finished, except the nose radius, to enable a fine adjustment of the cavity's frequency during the tuning sequence.

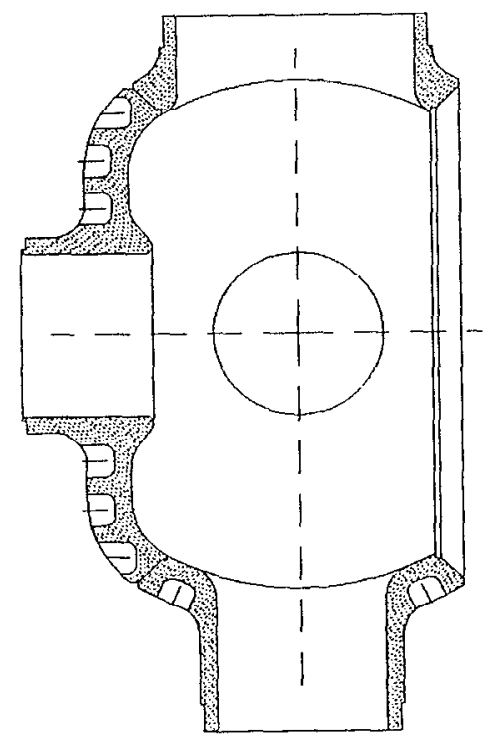

Figure 2: View of the cavity body configuration at time of inner and port blend radii finishing.

\section{The 3.3 Cavity Body}

The body end cap was joined to the body center section by EBW. We employed a structural weld from the outside, then placed a sealing weld from the inside to overlap the root of the external structural weld [5]. This process assured that trapped volumes and porosity were minimized and also eliminated weld joint gaps, providing a fully cleanable cavity.

The inner contour of the cavity body was then turned through the remaining opening to a surface finish of 24 $\mu$ inch $(.6 \mu \mathrm{m}) \mathrm{Ra}$ or better (Figure 2). This eliminated 
surface irregularities left by the welding process and enabled us to locate the attached beam at a nominal position. Machining of the blend radii between the RF surface and the port bores, as well as final sizing of the bores, was completed.

The cavity's in-process frequency was determined by clamping temporary flanges to the ports, installing dummy tuners, and placing the tuning end cap in position. This allowed calculation of the amount to be removed from the tuning end cap nose to achieve the desired frequency. Once the frequency is correct, and verified, the end cap is EBW in place using the welding procedure detailed earlier. The frequency is once again verified as the last step in the tuning process.

\subsection{RF Cavity}

Plating wax was poured into the cooling channels and finished to be flush with the outer contour of the cavity. The wax surface was made conductive by burnishing silver powder into it and then processing through an activating sequence. A jacket of plated copper, approximately .2 inch $(5 \mathrm{~mm})$ thick, was grown over all of the channels. We chose to use a brightened copper, which deposits more rapidly and more uniformly than the pure copper used previously. By using the brightened copper plating we have eliminated the intermediate turning stage required with the pure copper jacket used on the PEP-II cavities.

As this copper is not weldable with conventional techniques the design calls for joining six stainless steel water fitting stubs to the cavity using the plating. The protrusion of the stubs render machining of the outer surface impractical, therefore we needed to understand the plating process prior to introducing a production cavity into the process. We built an aluminum mandrel to mock up the outer features of the cavity to refine the design and placement of masking, and optimize the plating parameters. Through this effort we identified an area between the water fittings and the beam ports needing an auxiliary anode to assure the plating thickness matches the rest of the cavity, thereby avoiding a potentially thin spot in the plating at one of the higher heat load areas.

The smaller harmonic cavity (one-third the PEP-II size) also presented a concern that the wax would fall out of the water channel grooves when the cavity was turned over to wax the opposite side. We performed the waxing process on the aluminum mandrel and determined that, while our concern was valid, there was not a problem.

Once plating was completed the wax was melted and flushed out of channels. Small holes were drilled through the plating into the wax placed over the EBW joints and the wax flushed out to create a water-to-vacuum air guard. After fittings and jumper tubes were TIG welded to the water stubs the passages were hydrostatically tested to 150 psi (1 MPa).

Flange locating features were cut at the four port bodies and the two beam ports. This reduced the risk that the flanges would be out of square to the beam axis, a concern as we join the cavities together with rigid spool pieces. There is a bellows between the last cavity (in a string of five) and the mating vacuum chamber. The flanges, standard stainless steel circular knife-edge seals, with copper inserts, were then attached by EBW.

The final process cleans and lightly etches the inside of the cavity using a mild chromic acid bright dip followed by rinsing in clean DI water. This process is designed to remove any residue that condenses on the inside wall from the EBW process as well as any contaminates that may have been inadvertently introduced during the fabrication process. Historically, this cleaning and etching process has improved internal cavity surfaces to $16 \mu$ inch $(0.4 \mu \mathrm{m})$ $\mathrm{Ra}$ or better. The cavity was then blown dry with nitrogen, blanked off and backfilled with dry nitrogen at atmospheric pressure for shipping.

\section{CONCLUSIONS}

Our use of design models for manufacturing generated small discomforts yet these were greatly offset by the avenue of communication opened between the design and manufacturing organizations. Also, programmers and machinists were able to manipulate the model on the CAD screen to see what the "other side" of the part actually looked like, rather than having to try and visualize it from two-dimensional paper drawings.

Including the ports as integral parts of the cavity body proved to require more care in fixture design and machining efforts than initially estimated. We would chose this path again as our PEP-II experience showed that the myriad parts and fixtures needed to fabricate and weld these ports present a far greater expense and yields more technical risk.

We placed the water channel stubs too closely together and too near the beam port bodies for the plating rate to be the same as the remainder of the cavity. A supplemental anode was used to cause the copper to preferentially plate in the problem areas. We expect that by providing at least a 1-inch (25.4-mm) gap between features we could alleviate this problem.

\section{ACKNOWLEDGMENTS}

The authors thank the many designers, machinists, physicists, and technicians for their personal commitment and technical excellence in producing the ALS ThirdHarmonic RF Cavities.

\section{REFERENCES}

[1] R. Rimmer et. al., "A Third-Harmonic RF Cavity for the Advanced Light Source", Proc. EPAC 98, Stockholm, Sweden

[2] R.M. Franks, et. al., "Fabrication Processes for the PEP-II RF Cavities", Proc. PAC 97, Vancouver, B.C., Canada

[3] R. Rimmer et. al., "Notes from the RF cavity production close-out meeting, LLNL, 11/13/97", PEP-II EE note 97.07

[4] "Standard Specification for Oxygen Free Copper in Wrought Forms for Electron Devices", ASTM designation F68-82.

[5] R.M. Franks, et. al. "Electron Beam Welding of Thick CrossSection Copper with Minimal Porosity," Proc. 1997 AWS Convention, Los Angeles, American Welding Society, Miami, Florida, 1997, pp. 184-85, UCRL-JC-125896 Ext Abs 